\title{
FAKTOR-FAKTOR YANG MEMPENGARUHI BEHAVIORAL INTENTION PENGGUNA MOBILE BANKING BCA: STUDI PADA GEN Y
}

\author{
Heryanto \\ Program Studi Magister Manajemen Universitas Tarumanagara \\ heryanto.mmuntar@gmail.com \\ Miharni Tjokrosaputro \\ Program Studi Magister Manajemen Universitas Tarumanagara \\ Masuk : 07-07-2020, revisi : 10-07-2020 diterima untuk diterbitkan : 13-07-2020
}

\begin{abstract}
Recently, the using of mobile banking facilities are increasingly in demand because it considered effective for customers. This research used BCA mobile banking users as respondents. The aim of this research is to determine factors that affects Behavioral Intention of BCA mobile banking users. Sampling from 138 respondents among generation Y by probability sampling method. The researcher collected data by distributing questionnaires to respondents and the data were analyzed by using software SPSS Statistics version 24. The results showed that Effort Expectancy, Performance Expectancy, Social Influence, Facilitating, Security, and Self Efficacy affected positively toward Behavioral Intention for BCA mobile banking users among generation Y. The study could contribute to BCA or other banks to analyze and improve their mobile banking services to increase mobile banking usage among generation $\mathrm{Y}$.
\end{abstract}

Keywords: Performance Expectancy, Effort Expectancy, Social Influence, Facilitating, Security, Self Efficacy, Behavioral Intention

Abstrak: Akhir-akhir ini, fasilitas mobile banking semakin diminati karena penggunaannya dianggap efektif bagi pelanggan. Penelitian ini menggunakan nasabah BCA yang pengguna mobile banking sebagai responden. Penelitian ini bertujuan untuk mengetahui berbagai faktor yang berpengaruh pada intensi perilaku pengguna mobile banking BCA. Pengambilan sampel dilakukan pada 138 responden di kalangan generasi Y dengan metode probability sampling. Pengumpulan data melalui penyebaran kuesioner kepada responden dan data dianalisis menggunakan software SPSS Statistics version 24. Hasil penelitian memperlihatkan bahwa Effort Expectancy, Performance Expectancy, Social Influence, Facilitating, Security, dan Self Efficacy berpengaruh positif terhadap intensi perilaku pengguna mobile banking BCA di kalangan Gen Y. Hasil studi ini dapat membantu BCA ataupun industri perbankan untuk menganalisis dan meningkatkan layanan mobile banking untuk meningkatkan penggunaan mobile banking BCA dari generasi Y.

Kata Kunci: Performance Expectancy, Effort Expectancy, Social Influence, Facilitating, Security, Self Efficacy, Behavioral Intention

\section{LATAR BELAKANG}

Penggunaan fasilitas mobile banking makin diminati oleh sebagian besar masyarakat karena penggunaannya yang efektif bagi nasabah. Peningkatan penggunaan mobile banking, selain dikarenakan perubahan jaman, juga disebabkan oleh perilaku nasabah perbankan yang membutuhkan kemudahan dalam melakukan transaksi perbankan dengan cepat, aman, akurat, dan tidak dibatasi dengan jam kerja.

Menurut Shaikh dan Karjaluoto (2015), ketika industri perbankan menjadi semakin kompetitif maka bank sebaiknya mengembangkan jasa pelayanan dan produk yang eksklusif untuk melayani kebutuhan pelanggan dan menarik calon konsumen baru. BCA adalah salah 
satu bank swasta terbesar di Indonesia yang mendapat gelar sebagai bank terbaik di Indonesia berdasarkan hasil survei The World's Best Banks 2019 (Forbes, 2019). Dalam rangka mempertahankan gelar sebagai bank terbaik tersebut, maka BCA berupaya untuk selalu membuat inovasi baru untuk memberikan kemudahan layanan perbankan bagi nasabahnya. Salah satu layanan andalan BCA adalah layanan mobile banking. Sebagai penyedia mobile banking, BCA perlu memahami berbagai faktor yang bisa berpengaruh pada perilaku pengguna mobile banking BCA terutama di kalangan generasi Y guna menghadapi persaingan dengan bank-bank lainnya, sekaligus untuk mempertahankan posisinya sebagai bank terbaik.

\section{Tujuan Penelitian}

Penelitian ini bertujuan untuk mengetahui pengaruh dari faktor-faktor Effort Expectancy, Social Influence, Performance Expectancy, Security, Facilitating, dan Self Efficacy terhadap Behavioral Intention pengguna mobile banking BCA dengan berfokus pada Gen Y (Boonsiritomachai dan Pitchayadejanant, 2017). Secara praktis, penelitian ini diharapkan dapat mengetahui berbagai faktor yang berpengaruh terhadap Behavioral Intention Gen Y dalam menggunakan mobile banking, sehingga dapat menjadi masukan bagi industri perbankan dalam melakukan analisa sistem mobile banking yang efektif untuk memenuhi kebutuhan para nasabahnya.

\section{TINJAUAN PUSTAKA}

Venkatesh et al. (2003) mengembangkan model Unified Theory of Acceptance and Use of Technology (UTAUT) untuk menguji tingkat adopsi teknologi dimana memudahkan pemahaman terhadap penerimaan dan penggunaan suatu teknologi. UTAUT merupakan teori yang berpengaruh dan banyak diadopsi untuk melakukan penelitian penerimaan pengguna (user acceptance) terhadap suatu teknologi informasi (Jati dan Laksito, 2012).

Venkatesh et al. (2003) berpendapat Performance Expectancy adalah derajat harapan seorang individu akan kemudahan dan keuntungan atas penggunaan suatu sistem teknologi dalam membantu seseorang untuk melakukan pekerjaannya. Penelitian Dewayanti et al. (2018) membuktikan intensi individu dalam penggunaan mobile banking dipengaruhi oleh faktor Performance Expectancy, adanya keyakinan pada manfaat mobile banking maka akan memberikan pengaruh positif pada minat pengguna, maka diajukan hipotesis kesatu, yaitu:

\section{Hipotesis 1: Performance Expectancy berpengaruh positif pada Behavioral Intention}

Adapun Effort Expectancy dapat diartikan sebagai tingkat kesederhanaan atau kemudahan untuk menggunakan sistem tertentu yang menunjukkan seberapa banyak usaha yang dilakukan oleh pengguna untuk menggunakan sistem (Venkatesh et al., 2003). Penelitian dari Alalwan et al. (2017) dan Dewayanti et al. (2018) menunjukkan bahwa Effort Expectancy dapat berpengaruh positif pada intensi perilaku penggunaan mobile banking dimana pengguna merasa nyaman untuk mengoperasikannya teknologi, maka dibuat hipotesis kedua, yaitu:

\section{Hipotesis 2: Effort Expectancy berpengaruh positif pada Behavioral Intention}

Social Influence merupakan tingkat dimana seorang individu menganggap bahwa pengaruh orang lain menyakinkan dirinya bahwa dia harus menggunakan sistem baru. Pengaruh sosial ditunjukkan dari besarnya dukungan teman, rekan kerja, saudara, dan keluarga (Moerti, et al., 2015). Wardani dan Hidayatullah (2018) menjelaskan bahwa pengaruh sosial dapat menjadi faktor yang berperan penting pada intensi perilaku konsumen. Berdasar paparan tersebut, maka hipotesis ketiga penelitian ini adalah sebagai berikut:

\section{Hipotesis 3: Social Influence berpengaruh positif pada Behavioral Intention}

Facilitating conditions adalah tingkat kepercayaan seorang individu terhadap ketersediaan infrastruktur teknis dan organisasional untuk mendukung penggunaan sistem (Venkatesh et al., 2003). Penelitian Junadi dan Sfenrianto (2015) dan Dewayanti et al. (2018) memperlihatkan bahwa semakin baik Facilitating yang diberikan akan berpengaruh positif pada intensi perilaku dalam menggunakan suatu teknologi, maka hipotesis keempat, yaitu:

\section{Hipotesis 4: Facilitating berpengaruh positif pada Behavioral Intention}


Perceived Security merupakan derajat keyakinan seseorang bahwa teknologi yang digunakan untuk mengirimkan informasi yang sensitif seperti data konsumen dan transaksi finansial terjamin keamanannya, atau dilindungi dari segala ancaman potensial (Mahendra, et al., 2017). Penelitian Junadi dan Sfenrianto (2015) dan Mahendra et al. (2017) menunjukkan bahwa semakin tinggi keamanan yang dirasakan pengguna aplikasi mobile akan berpengaruh positif terhadap intensi konsumen menggunakan mobile banking, maka dibuat hipotesis kelima yang tersebut di bawah ini:

\section{Hipotesis 5: Security berpengaruh positif pada Behavioral Intention}

Self Efficacy merupakan konstruk yang digunakan untuk mengukur kemampuan seseorang untuk menggunakan teknologi untuk menyelesaikan suatu tugas (Venkatesh et al., 2003). Self Efficacy merupakan keyakinan atau kepercayaan individu mengenai kemampuan dirinya untuk mengorganisasi, melakukan suatu tugas, mencapai suatu tujuan, menghasilkan sesuatu, dan mengimplementasikan tindakan untuk menampilkan kecakapan tertentu (Bandura, 1997). Penelitian Boonsiritomachai dan Pitchayadejanant (2017) dan Anouze dan Alamro (2019) terbukti bahwa semakin baik kemampuan seorang individu dalam menggunakan aplikasi mobile banking dapat berpengaruh positif pada niat mengadopsi penggunaan mobile banking, maka hipotesis keenam dari penelitian ini yaitu:

\section{Hipotesis 6: Self Efficacy berpengaruh positif pada Behavioral Intention}

Menurut Moerti et al. (2015) Behavioral Intention adalah sejauh mana keinginan, intensi perilaku seseorang untuk menggunakan teknologi secara berkesinambungan dengan menggunakan asumsi bahwa pelanggan memiliki akses terhadap informasi yang sesuai. Generasi Y adalah generasi unik, karena cerdas dalam menggunakan teknologi dan kebanyakan individu muda bersedia untuk mengadopsi teknologi baru (Goi dan Ng, 2011). Secara umum, generasi Y lahir di era perkembangan teknologi informasi dan pemakai media sosial yang aktif dan fanatik. Dalam kehidupannya, Gen Y sangat mengutamakan kepraktisan dan sangat mengikuti dengan perkembangan teknologi. Penelitian terdahulu yang dilakukan oleh Boonsiritomachai dan Pitchayadejanant (2017) meneliti tentang faktor-faktor yang mempengaruhi niat perilaku untuk mengadopsi mobile banking di antara generasi $\mathrm{Y}$ di Bangkok.

Dari penjelasan hipotesis di atas, maka disusun kerangka penelitian sebagai berikut:

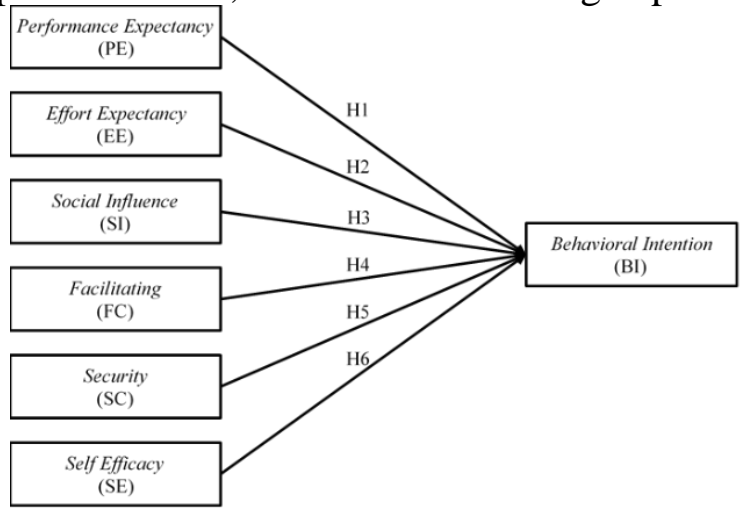

\section{Gambar 1 \\ Kerangka Penelitian}

\section{METODOLOGI PENELITIAN}

\section{Populasi, Sampel, dan Pengumpulan Data}

Metode penelitian ini adalah penelitian kuantitatif dengan pendekatan kausalitas. Populasi adalah seluruh nasabah pengguna mobile banking BCA dari generasi Y yang berusia antara 20 - 40 tahun di Jakarta. Adapun pengambilan sampel menggunakan metode probability sampling dengan jumlah sampel 138 orang nasabah pengguna mobile banking BCA dari Gen Y, pada rentang usia 20 - 40 tahun. Teknik pengumpulan data dengan menggunakan kuesioner melalui Google Form. 


\section{Variabel Penelitian, Operasionalisasi Penelitian, dan Metode Analisis Data}

Terdapat enam variabel bebas pada riset ini, yakni Performance Expectancy, Effort Expectancy, Social Influence, Facilitating, Security, dan Self Efficacy dan satu variabel terikat yaitu Behavioral Intention. Operasionalisasi variabel pada riset ini mengadopsi penelitian dari Boonsiritomachai dan Pitchayadejanant (2017). Skala Likert digunakan untuk mengukur berbagai variabel pada studi ini, dengan skala pengukuran dari $1-5$ dimana nilai 1 berarti "Sangat Tidak Setuju" dan nilai 5 berarti "Sangat Setuju". Penelitian ini menggunakan software SPSS Statistics version 24 untuk melakukan uji validitas dan realibilitas, uji asumsi klasik yang terdiri dari uji normalitas, uji heterokedastisitas, dan uji multikolinearitas, selanjutnya menggunakan analisa regresi berganda.

\section{HASIL PENELITIAN DAN KESIMPULAN Hasil Penelitian}

Hasil olah data terhadap 138 responden menunjukkan bahwa mayoritas responden adalah pria $(55,80 \%)$. Selain itu, sebagian besar responden berusia antara $29-33$ tahun $(52,90 \%)$. Tingkat pendidikan terakhir responden adalah diploma $(39,86 \%)$ dan sarjana $(30,43 \%)$. Adapun prosentase terbesar pekerjaan responden adalah pegawai swasta (39,86\%). 47,10\% menggunakan mobile banking BCA 6 - 10 kali selama sebulan. Adapun tingkat pendapatan per bulan dari 44,20\% responden berada pada rentang antara Rp. $3-5,99$ juta.

Hasil pengujian validitas item pertanyaan menunjukkan sudah valid dimana setiap item pertanyaan menghasilkan nilai Corrected Item-Total Correlation $>0,3$. Hasil pengujian realibilitas menunjukkan bahwa semua variabel menghasilkan nilai koefisien Cronbach Alpha $\geq 0,6$, yang berarti reliabel.

Hasil uji asumsi klasik yang dilakukan menunjukkan hasil uji normalitas memperoleh nilai signifikansi sebesar 0,082 > 0,05 yang berarti model regresi memenuhi asumsi normalitas. Hasil uji multikolinearitas menunjukkan semua variabel tidak terjadi multikolinearitas dimana nilai Tolerance $\geq 0.10$ dan Variance Inflation Factor $(V I F)<10$. Hasil uji heteroskedastisitas menunjukkan hasil yang positif dimana semua variabel bebas yaitu PE, EE, SI, FC, SC, dan SE memiliki nilai signifikansi $>0,05$ yang menunjukkan model regresi tidak terjadi gejala heteroskedastisitas.

Persamaan hasil uji regresi berganda dalam penelitian ini yaitu:

$$
\mathrm{BI}=-0,414+0,148 \mathrm{PE}+0,118 \mathrm{EE}+0,246 \mathrm{SI}+0,131 \mathrm{FC}+0,131 \mathrm{SC}+0,119 \mathrm{SE}+\mathrm{e}
$$

\section{Tabel 1}

Hasil Uji F

ANOVA ${ }^{b}$

\begin{tabular}{|c|l|r|r|r|c|c|}
\hline \multicolumn{2}{|c|}{ Model } & Sum of Squares & \multicolumn{1}{c|}{$\boldsymbol{d f}$} & Mean Square & $\boldsymbol{F}$ & \multicolumn{1}{c|}{ Sig. } \\
\hline \multirow{3}{*}{1} & Regression & 648,524 & 6 & 108,087 & 110,742 & $0,000^{\mathrm{b}}$ \\
\cline { 2 - 7 } & Residual & 127,860 & 131 &, 976 & & \\
\cline { 2 - 8 } & Total & 776,384 & 137 & & & \\
\hline
\end{tabular}

Hasil uji F menunjukkan bahwa nilai signifikan sebesar 0,000. Ini menunjukkkan bahwa secara keseluruhan variabel bebas berpengaruh terhadap variabel terikat.

Tabel 2

Hasil Uji t

\begin{tabular}{|c|c|c|c|c|c|c|}
\hline & \multirow[t]{2}{*}{ Model } & \multicolumn{2}{|c|}{$\begin{array}{c}\text { Unstandardized } \\
\text { Coefficients }\end{array}$} & \multirow{2}{*}{\begin{tabular}{|c|}
$\begin{array}{c}\text { Standardized } \\
\text { Coefficients }\end{array}$ \\
Beta \\
\end{tabular}} & \multirow[t]{2}{*}{$t$} & \multirow[t]{2}{*}{ Sig. } \\
\hline & & $\boldsymbol{B}$ & Std. Error & & & \\
\hline & (Constant) & $-0,414$ & 0,382 & & $-1,085$ & 0,280 \\
\hline & Performance Expectancy & 0,148 & 0,066 & 0,152 & 2,252 & 0,026 \\
\hline & Effort Expectancy & 0,118 & 0,046 & 0,168 & 2,593 & 0,011 \\
\hline 1 & Social Influence & 0,246 & 0,076 & 0,237 & 3,216 & 0,002 \\
\hline & Facilitating & 0,131 & 0,062 & 0,138 & 2,119 & 0,036 \\
\hline & Security & 0,131 & 0,063 & 0,139 & 2,058 & 0,042 \\
\hline & Self Efficacy & 0,119 & 0,035 & 0,199 & 3,438 & 0,001 \\
\hline
\end{tabular}


Hasil uji t menunjukkan semua variabel bebas yaitu PE, EE, SI, FC, SC, dan SE ternyata memiliki nilai signifikansi $<0,05$ yang berarti keseluruhan variabel mempunyai pengaruh signifikan terhadap variabel terikat BI.

\section{Tabel 3}

Hasil Uji Koefisien Determinasi $\left(\mathbf{R}^{2}\right)$

\begin{tabular}{|c|c|c|c|c|}
\hline \multicolumn{5}{|c|}{ Model Summary ${ }^{b}$} \\
\hline Model & $\boldsymbol{R}$ & R Square & $\begin{array}{l}\text { Adjusted } \\
R \text { Square }\end{array}$ & $\begin{array}{l}\text { Std. Error of } \\
\text { the Estimate }\end{array}$ \\
\hline 1 & $0,914^{\mathrm{a}}$ & 0,835 & 0,828 & 0,98794 \\
\hline
\end{tabular}

Koefisien determinasi $\left(\mathrm{R}^{2}\right)$ menunjukkan nilai sebesar 0,835 yang berarti bahwa semua variabel SE, EE, SC, PE, FC, dan SI mampu menjelaskan hubungan dengan variabel BI sebesar $83,5 \%$, sisanya sebesar $16,5 \%$ dipengaruhi oleh variabel lain yang tidak diteliti.

Hasil uji hipotesis pertama, menunjukkan bahwa Performance Expectancy berpengaruh secara positif terhadap Behavioral Intention pengguna mobile banking BCA, mendukung penelitian yang dilakukan oleh Dewayanti et al. (2018) Morosan dan DeFranco (2016). Hal ini dipengaruhi dipengaruhi oleh beberapa faktor di antaranya kenyamanan dan penyelesaian transaksi yang lebih cepat.

Hasil uji hipotesis kedua, membuktikan bahwa Effort Expectancy berpengaruh secara positif terhadap Behavioral Intention pengguna mobile banking BCA, mendukung penelitian yang dilakukan oleh Alalwan et al. (2017) dan Dewayanti et al. (2018). Hal ini dipengaruhi oleh kemudahan dalam penggunaan, tampilan yang friendly, tampilan yang jelas dan cepat.

Hasil uji hipotesis ketiga, terlihat bahwa Social Influence berpengaruh secara positif terhadap Behavioral Intention pengguna mobile banking BCA, mendukung penelitian yang dilakukan oleh Dewayanti et al. (2018) dan Wardani dan Hidayatullah (2018). Hasil ini dipengaruhi oleh adanya ajakan oleh keluarga dan teman, petugas bank, dan iklan.

Hasil uji hipotesis keempat, terbukti bahwa Facilitating berpengaruh secara positif terhadap Behavioral Intention pengguna mobile banking $\mathrm{BCA}$, mendukung penelitian terdahulu yang dilakukan oleh Junadi dan Sfenrianto (2015) dan Dewayanti, et al. (2018). Hasil ini disebabkan karena fasilitas mobile banking yang dapat bekerja 24 jam tanpa masalah, aplikasi mobile banking yang dapat terus diperbaharui, dan mudah didaftarkan.

Hasil uji hipotesis kelima, Security berpengaruh secara positif terhadap Behavioral Intention pengguna mobile banking BCA, mendukung penelitian yang dilakukan oleh Junadi and Sfenrianto (2015) dan Mahendra, et al. (2017). Hal ini dikarenakan sebagian besar responden setuju bahwa sistem keamanan mobile banking dengan adanya notifikasi setiap kali menggunakan layanan mobile banking BCA, bukti konfirmasi setiap kali menyelesaikan transaksi, dan harus memasukkan PIN setiap kali dalam melakukan transaksi.

Hasil uji hipotesis keenam, menunjukkan bahwa Self Efficacy berpengaruh secara positif terhadap Behavioral Intention pengguna mobile banking BCA, mendukung penelitian yang dilakukan oleh Boonsiritomachai dan Pitchayadejanant (2017) dan Anouze dan Alamro (2019). Hal ini dikarenakan umumnya generasi Y lebih mudah tanggap untuk menerima informasi teknologi. Mereka dapat menggunakan mobile banking BCA tanpa bantuan dan petunjuk orang lain, mereka cenderung mengikuti petunjuk manual, dan mereka terbiasa menggunakan aplikasi serupa sebelumnya.

\section{Kesimpulan dan Saran}

Secara keseluruhan, hasil penelitian ini menunjukkan bahwa Performance Expectancy, Effort Expectancy, Social Influence, Facilitating, Security, dan Self Efficacy terbukti berpengaruh positif terhadap Behavioral Intention pada pengguna mobile banking BCA dari Gen Y. Peneliti menyarankan kepada Bank BCA agar meningkatkan kualitas mobile banking dengan melakukan berbagai inovasi terhadap layanan mobile banking BCA seperti menambah fitur-fitur baru yang lebih menarik, misalnya login menggunakan fingerprint, penambahan limit transaksi harian, dan lain-lain. Penelitian selanjutnya dapat melakukan pengujian ulang 
menggunakan sampel yang lebih banyak, sebaran lokasi penelitian yang lebih luas, dan menambahkan variabel-variabel lainnya. Implikasi manajerial dari penelitian ini terhadap perbankan, khususnya BCA agar memperhatikan faktor-faktor Performance Expectancy, Social Influence, Effort Expectancy, Facilitating, Security, dan Self Efficacy dalam upaya untuk meningkatkan Behavioral Intention pengguna mobile banking dari Gen Y.

\section{DAFTAR PUSTAKA}

Alalwan, A. A., Dwivedi, Y. K., \& Rana, N. P. (2017). Factors influencing adoption of mobile banking by Jordanian bank customers: Extending UTAUT2 with trust. International Journal of Information Management, 37(3), 99-110.

Anouze, A. L. M., \& Alamro, A. S. (2019). Factors affecting intention to use e-banking in Jordan. International Journal of Bank Marketing.

Bandura, A. (1997). Self-Efficacy: The Exercise of Control. H. Freeman New York, NY.

Boonsiritomachai, W., \& Pitchayadejanant, K. (2017). Determinants affecting mobile banking adoption by generation Y based on the Unified Theory of Acceptance and Use of Technology Model modified by the Technology Acceptance Model concept. Kasetsart Journal of Social Sciences.

Dewayanti, A., Kusyanti, A., \& Herlambang, A. D. (2018). Faktor-faktor yang memengaruhi minat nasabah dalam menggunakan layanan mobile banking dengan menggunakan UTAUT (Unified Theory of Acceptance and Use of Technology) (Studi pada pengguna mobile banking BRI KCP Universitas Brawijaya). Jurnal Pengembangan Teknologi Informasi dan Ilmu Komputer. e-ISSN, 2548, 964X.

Forbes Media, in partnership with Statista Inc. (2019). The World's Best Banks 2019. Retrieved Jun 28, 2019 from https://www.forbes.com/worlds-best-banks/\#1ab0bdb91295

Goi, C. L., \& Ng, P. Y. (2011). Perception of young consumers on mobile phone applications in Malaysia. World Applied Sciences Journal, 15(1), 47-55.

Jati, N. J., \& Laksito, H. (2012). Analisis faktor-faktor yang mempengaruhi minat pemanfaatan dan penggunaan sistem e-ticket (Studi empiris pada biro perjalanan di Kota Semarang) (Doctoral dissertation, Fakultas Ekonomika dan Bisnis).

Junadi, \& Sfenrianto. (2015). A model of factors influencing consumer's intention to use epayment system in Indonesia. Procedia Computer Science, 59, 214-220.

Mahendra, Y. A. S., Winarno, W. W., \& Santosa, P. I. (2017). Pengaruh perceived security terhadap pengadopsian in-app purchase pada aplikasi mobile. Jurnal Nasional Teknik Elektro dan Teknologi Informasi (JNTETI), 6(2), 184-193.

Moerti, H., Astuti, E. S., \& Suyadi, I. (2015). Analisis pengaruh variabel-variabel pada model UTAUT yang dimodifikasi terhadap penggunaan website e-commerce (Studi pada pengguna toko fashion online www.Zalora.co.id). Jurnal SPIRIT, 7(1). 36-47

Morosan, C., \& DeFranco, A. (2016). It's about time: Revisiting UTAUT2 to examine consumers' intentions to use NFC mobile payments in hotels. International Journal of Hospitality Management, 53, 17-29.

Shaikh, A. A., \& Karjaluoto, H. (2015). Mobile banking adoption: A literature review. Telematics and informatics, 32(1), 129-142.

Venkatesh, V., Morris, M. G., Davis, G. B., \& Davis, F. D. (2003). User acceptance of information technology: Toward a unified view. MIS quarterly, 425-478.

Wardani, I. \& Hidayatullah, D. S. (2018). Analisis minat pengguna layanan BNI internet banking dengan menggunakan model Unified Theory of Acceptance and Use of Technology (UTAUT). eProceedings of Management, 5(2). 